\title{
Study of factors effecting to getting internship to Second/Third year students: A data mining Approach
}

\author{
Ashish Pant ${ }^{1}$, DevendraKushwaha ${ }^{2}$, JitendraMaurya ${ }^{3}$ \\ Computer Science and information technology, I.E.T.M.J.P.R.U ${ }^{1,2,3}$
}

\begin{abstract}
The main concerns of any higher educational system is evaluating and enhancing the educational organization so as to improve the quality of their services and satisfy their customer's needs. This is an attempt to find suitable predication techniques using data-mining tool called WEKA.As the second and third year is very important for the engineering student cause after this a student go out for internship and get experience in his field. So we are trying to evaluate the factors for getting internship after 2 nd year or $3^{\text {rd }}$ year and if he is not been a better chance to get internship so he can work in the field in the third year. So the education institute can check his student performance and give student the notification that he has to do such work and have to work hard to increase his performance. The process of finding a suitable prediction algorithm was also described.
\end{abstract}

Keywords: Classification, Prediction, Student performance,data mining.

\section{INTRODUCTION}

Data Mining is the vast field containing research in various among educators about the need to enhance students' amount of data.Educational data mining is one of its field. writing skills, there is little understanding of the nature of Educational Data Mining (EDM) describes a research field students' problems - a necessary step in the development concerned with the application of data mining,machine of effective educational approaches. This article reports on learning algorithm and mining various statistics that are a qualitative study that sought to understand which factors collected from various field.This field concern with contributed to the weak writing skills of a group of social improving the performance of students or evaluating work undergraduates. Based on its findingsand analysis of factors that effect the students in order to discover new previous literature, the authors suggest a set of interrelated insights about how people learn in the context of such components that influence students' writing. The study's settings. Educational data mining is contributed to the findings may contribute to the development of potential theories of learning investigated by researcher in an field solutions to this persistent problem

of education. The field is closely tied to that of learning [3]On the basis of educational persistence and analytics, and the two have been compared and contrasted. motivational theory models, the PSFs(physiological and With the continuous development of database technology study skill factors)were categorized into 9 broad and the extensive applications of database management constructs: achievement motivation, academic system, the data volume stored in database increases goals,institutional commitment, perceived social support, rapidly and in the large amounts of data much important social involvement, academic self-efficacy, generalselfinformation is hidden. So data mining tools are very concept, academic-related skills, and contextual important in this field. These tools are very important for influences. Two college outcomes were evaluating the factor that are effecting the targeted:performance (cumulative grade point average; students'performance, so that one could improve the GPA) and persistence (retention). Meta-analyses performance. So in this paper we are trying to evaluate the indicatemoderate relationships between retention and factors that are important for student for getting internship academic goals, academic self-efficacy, and to $2^{\text {nd }}$ and $3^{\text {rd }}$ year students in getting internship.

\section{REVIEW LITERATURE}

academicrelatedskills. The best predictors for GPA were academicself-efficacy and achievement motivation. Supplementary regressionanalyses confirmed the

[1] This study measure the quantity of studentbehaviour, incremental contributions of the PSF over and above those teacher attributes, and course characteristics on class of socioeconomicstatus, standardized achievement, and attendance and performance. Several notable factors that high school GPA in predicting college outcomes.

influence attendance and grades are motivation, prior [4]J.F. Superbyconducted a study to investigate to grade point average (GPA), self-financing by students, determine the factors to be taken into account we will use hours worked on jobs, quality of teaching, and nature of a model adapted from that of Philippe Parmentier (1994). class lectures. It also provide the student positive effect on In other words the idea is to determine if it is possible to class attendance on performance of students. [2]Social predict a decision variable using the explanatory variables work educators concur that writing and critical thinking which we retained in the model.

are basic components of effective practice, yet students are [5] Bray in his study has made conclusion that the number often deficient in these skills. Although there is agreement of students taking private tutoring in India is much higher 
than in other countries.It also shows that the impact of private tutoring on the performance of the students and intensity of private tutoring depends on the collective factor namely socio-economic conditions.

\section{III.METHODOLOGY}

Through extensive search of the literature, discussion and by experience of experts on student performance, a number of socio-economic, environmental, academic, and other related factors that are considered to have influence on the performance of university student were identified. These factors were carefully studied and harmonized into a manageable number suitable for computer coding within the context of the familiar algorithms. These influencing factors were categorized as input variables. The output on the other hand represents some possible levels of performance of a candidate in terms of the present college grading system.

\section{IV.DATA COLLECTION}

For the evaluation ofreal world data's are collected from first year engineering students. For collection we choose M.J.P.RU campus and then evaluate the performance. A sample of 360 students was taken from college $2^{\text {nd }}$ and $3^{\text {rd }}$ year students. Students were sit down on their hostels and we told them briefly about the survey so they are true in their data given.The primary data was collected using a questionnaire. Which include questions (i.e. with predefined options) related to several personal, socio-economic, psychological and school and college related variables that were expected to affect student performance. The questionnaire was reviewed by us and tested on a small set of 50 students in order to get a feedback i.e. how true these students are. The final version contained 23 questions in a single A4 sheet and it was answered by more than 300 students. Latter we selected a sample of 250 from the whole. All questionnaires were filled with the response rate of $100 \%$ out of which 100 were females and 150 were males.

The secondary data such as semester mark details, attendance percentage, and class test performance were collected by checking their marks and their attendance is asked by the students and confirmed by the class representative. All the predictor and response variables which were derived from the questionnaire.

\begin{tabular}{|c|c|c|c|}
\hline & $\begin{array}{l}\text { Variable } \\
\text { Name }\end{array}$ & $\begin{array}{l}\text { Descriptio } \\
\text { n }\end{array}$ & Domain \\
\hline 1 & Sex & $\begin{array}{l}\text { Student } \\
\text { sex }\end{array}$ & $\{$ male,female $\}$ \\
\hline 2. & Com & $\begin{array}{l}\text { Student } \\
\text { community }\end{array}$ & $\begin{array}{l}\text { \{general,obc,sc, } \\
\text { st }\}\end{array}$ \\
\hline 3 & Living & Living area & \{ \\
\hline 4 & Q1 & $\begin{array}{l}\text { Rank of } \\
\text { department }\end{array}$ & $\{1,2,3,4,5,6\}$ \\
\hline 5 & Po & $\begin{array}{l}\text { Parent } \\
\text { occupation }\end{array}$ & $\begin{array}{l}\text { daily wages, } \\
\text { farmer, weaver, } \\
\text { ex-serviceman, } \\
\text { govt., }\end{array}$ \\
\hline
\end{tabular}

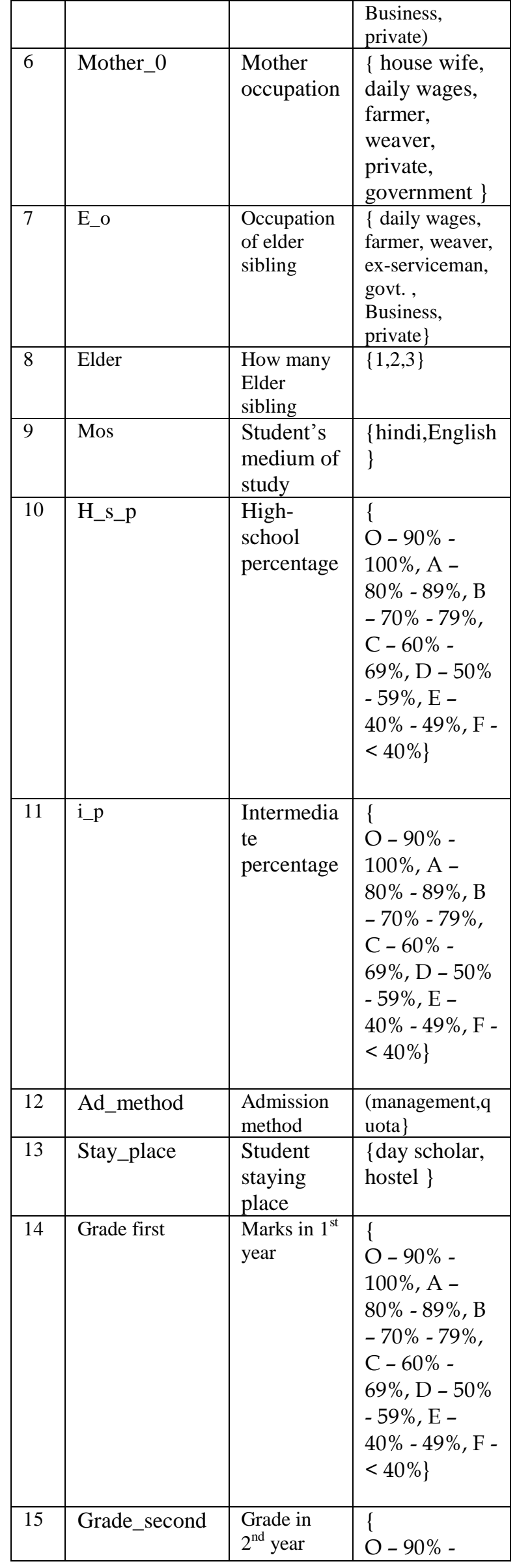




\begin{tabular}{|c|c|c|c|}
\hline & & & $\begin{array}{l}100 \%, \mathrm{~A}- \\
80 \%-89 \%, \mathrm{~B} \\
-70 \%-79 \%, \\
\mathrm{C}-60 \%- \\
69 \%, \mathrm{D}-50 \% \\
-59 \%, \mathrm{E}- \\
40 \%-49 \%, \mathrm{~F}- \\
<40 \%\}\end{array}$ \\
\hline 16 & Project & $\begin{array}{l}\text { Project u } \\
\text { have made }\end{array}$ & $\{1,2,3\}$ \\
\hline 17 & Paper_present & $\begin{array}{l}\text { Paper } \\
\text { presented }\end{array}$ & $\{1,2,3\}$ \\
\hline 18 & Patent & Any patent & $\{$ Yes,no $\}$ \\
\hline 19 & Technical & $\begin{array}{l}\text { Member } \\
\text { of any } \\
\text { technical } \\
\text { |cultural } \\
\text { |sports } \\
\text { communit } \\
\text { y }\end{array}$ & $\{1,2,3,4\}$ \\
\hline 20 & $\begin{array}{l}\text { Tech_attendan } \\
\text { ce }\end{array}$ & $\begin{array}{l}\text { Student } \\
\text { class } \\
\text { attendance }\end{array}$ & $\begin{array}{l}\{<50,50,60, \\
70,80,90\}\end{array}$ \\
\hline 21 & $\begin{array}{l}\text { Area_of_intere } \\
\text { st }\end{array}$ & $\begin{array}{l}\text { Any area } \\
\text { of interest } \\
\text { (mention } \\
\text { number) }\end{array}$ & $\{1,2,3\}$ \\
\hline 22 & Pqual & $\begin{array}{l}\text { Parent } \\
\text { qualificatio } \\
\mathrm{n}\end{array}$ & $\begin{array}{l}\text { \{ illiterate, } \\
\text { schooling, } \\
\text { degree, } \\
\text { diploma }\}\end{array}$ \\
\hline 23 & Co_cir & $\begin{array}{l}\text { Good in } \\
\text { Co-circular } \\
\text { activity }\end{array}$ & $\{$ yes,no $\}$ \\
\hline
\end{tabular}

Table 1.Factors for evaluating studentsperformace

\section{V.Algorithm And Implementation}

Although many classification models exist, only some have been selected within the scope of this study. The selected algorithms are Naïve Bayesian algorithm, MLP, SMO, J48 and Decision table are used.

First, data cleaning was applied on the datasets. According to the missing data analysis, missing data have been removed from the datasets. Other than missing data analysis, datasets were also cleaned to remove noisy data. Unnecessary space characters or other spelling mistakes were also cleaned in the datasets. Another usual step in data pre-processing is data discretization. Although some algorithms are said to perform better when the numerical input variables are discretised, in this study numerical variables have not been put into binned intervals in order to maintain the same conditions for all algorithms.

WEKA is open source software issued under the GNU General Public License. WEKA has been utilized as the tool to run different classification algorithms. The algorithms can either be applied directly to a dataset or called from your own Java code. WEKA contains tools for data pre-processing, classification, regression, clustering, a
association rules, and visualization. It is also well-suited the for developing new machine learning schemes

\section{V1. Result And Discussion}

This paper is an attempt to use classification techniques to analyse and evaluate student academic data and to enhance the quality of the higher educational system. Findings from the factors influencing academic performance were very significant. When pointing at the performance results of the classifier, its classification accuracy is actually measured. Accuracy is calculated by determining the percentage of instances correctly classified. Costs for wrong assignment can also be applied in classification problems; however, misclassification costs are not within the scope of this study.

\begin{tabular}{|l|l|l|l|l|l|}
\hline & $\begin{array}{l}\text { Naïve } \\
\text { Bayes }\end{array}$ & MLP & SMO & J48 & $\begin{array}{l}\text { Decision } \\
\text { tree }\end{array}$ \\
\hline $\begin{array}{l}\text { Accur } \\
\text { acy }\end{array}$ & 10.8 & 69.5 & 58.8 & 64.8 & 51.7 \\
\hline
\end{tabular}

Table 1. Comparison of classification accuracy

The accuracy values of the multiple dataset implementations according to each classifier can be seen in Table 4.1 (in percentage). The different classification algorithm predicts the grade more accurately. From this study Multi-Layer Perceptron predict the all the grades more accurately. The results of accuracy of different classifier are given above.

To verify relationship among the attributes, hypothesis is formed and tested.Result of these test are given below.

\begin{tabular}{|l|l|}
\hline Attribute & Hypothesis \\
\hline $\begin{array}{l}\text { Student quota through they } \\
\text { joined, Grade obtained at } \\
\text { semester examination }\end{array}$ & Ho rejected \\
\hline $\begin{array}{l}\text { Student area they are } \\
\text { belonging, Grade obtained } \\
\text { at semester examination }\end{array}$ & Ho rejected \\
\hline $\begin{array}{l}\text { Student staying place, } \\
\text { Grade obtained at } \\
\text { semester examination }\end{array}$ & Ho rejected \\
\hline $\begin{array}{l}\text { Parent's qualification, } \\
\text { Grade obtained at semester } \\
\text { examination }\end{array}$ & Ho rejected \\
\hline $\begin{array}{l}\text { Student department, } \\
\text { Grade obtained at } \\
\text { semester examination }\end{array}$ & Ho rejected \\
\hline $\begin{array}{l}\text { Medium of schooling, } \\
\text { Grade obtained at } \\
\text { semester examination }\end{array}$ & Ho rejected \\
\hline $\begin{array}{l}\text { Student sex, Grade obtained } \\
\text { at semester examination }\end{array}$ & Ho rejected \\
\hline \multicolumn{1}{|c|}{ Tabe2. Testing Hypothesis } \\
\hline
\end{tabular}

Table2. Testing Hypothesis

Rules that satisfy both a minimum support threshold and a minimum confidence threshold are called strong. In our case, we get several strong rules in our association since they satisfy these requirements. However, not all of them are useful for us. Because of that, we have to choose what rules we need are and we should apply to. By selecting those useful rules, we can use them to do the prediction 
like we did before. Of course, even some attributes and rules are not our interests now; we might still need them later. When we want to predict other different attributes, we just need to repeat the same processes. In this analysis following are the strong association rules.

1. Department $=$ Mechanical $\rightarrow \mathrm{Sex}=\mathrm{M}$

2.Area=urban Quota=management $\rightarrow$ Staying place=day scholar

3.10th/12th medium=English Staying place=hostel Quota=counselling

4. Department $=$ Parent qualification $=$ Schooling $\rightarrow \mathrm{Sex}=\mathrm{M}$ 5.Department=Mechanical 10 th/12th medium $=$ Hindi $\rightarrow$ Sex $=\mathrm{M}$

6.10 th $/ 12$ th medium $=$ English 10 th $/ 12$ th percentage $=70+$ Department $\rightarrow$ E.E.

$7.10 \mathrm{th} / 12^{\text {th }} \quad$ percentage $=65-75 \quad$ medium $=$ Hindi department $=$ mechanical $\rightarrow 7+$ gpai /ii year

8.Elder sibling occupation $=$ Engineer $\rightarrow$ internship=approved

9.Elder Brother occupation=scientist $\rightarrow$ Paper presentation=yes

10.10th $/ 12$ th medium $=$ Hindi 10 th $/ 12$ th percentage $=60-65$ Staying place=hostel $\rightarrow$ member of department cricket team

11.Patent $=$ yes $\rightarrow$ internship $=$ approved

12.Area of interest=coding $\rightarrow$ internship=approved

\section{ConClusion}

In this paper we have analysed various factors influencing the academic performance of the students at engineering college level and predict the grade of the student if these factors are given as input. Performance of different classification algorithms are compared for classifying students using a Weka mining tool. We have shown that some algorithms improve their classification performance. We have also indicated that a good classifiermodel has to be both accurate and comprehensible for instructors. These included students' staying place, whether they stayed in hostel or day scholar in their first year of study and the area him/her belonging. This study will give a timely and an appropriate warning to students at risk. This work may improve student performance; reduce failing ratio by taking appropriate steps at right time to improve the quality of education. Therefore, it seems to us that data mining has a lot of potential for education.

\section{ACKNOWLEDGMENT}

We would like to thanks to my parents which help me in making dreams come true. I am indebted to facultymembers who help me in motivating to work in this field.I am also thankful to Mr.Prashant ,Miss.Urooj,Mr.ArunYadav who help us in reviewing the work and help me in interacting the students of other branches. I would like to thanks other persons also who help me in collecting data .Special thanks to the Mr.AnilYadav,Mr. Atiq Ahmad for helping us while collecting data ofquestionare. Special thanks to Guest Lect. Miss Smriti whose extreme support and help made our work possible.

\section{REFERENCES}

1] Evaluation of Factors Influencing Student Class Attendance and Performance by Stephen Deva doss and John Foltz.

[2] Beyond "Writing to learn": Factors influencing students writing outcomes by Jay shree S. Jani\& MarcelaSarmiento Mellinger.

[3] Do Psychosocial and Study Skill Factors Predict College Outcomes? A Meta-Analysis.Robbins, Steven B.; Lauver, Kristy; Le, Huy; Davis, Daniel; Langley, Ronelle; Carlstrom, Aaron.

4] J.F. Superby J.-P. Vandamme\& N. Meskens of Catholic University of Mons "Determination of factors influencing the achievement of the first-year university students using data mining methods".

[5] Rosemary Win and Paul W. Miller: The Effects of Individual and School Factors on University Students' Academic Performance.

\section{BIOGRAPHIES}

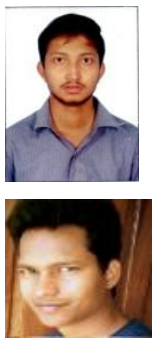

Ashish Pantis pursuing his final year of B.S. from I.E.T.M.J.P.R.U, Bareilly in Computer Science and Information Technology.

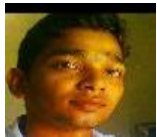

DevendraKushwaha is in final year of graduate. Area of interest is management. Final year project is "Management system".

JitendraMurya is in final year of graduation. His are of interest is A.I. He is being working on text to speech conversion in his final year project. 